\title{
Public Versus Private Airport Behavior When Concession Revenues Exist
}

(This is a substantially revised version of WP 09/05)

\section{Achim I. Czerny}

WHU - Otto Beisheim

School of Management

achim.czerny@whu.edu

WHU - Working Paper

Series in Economics

WP 12/01) 


\title{
Public Versus Private Airport Behavior When Concession Revenues Exist
}

\author{
Achim I. Czerny* \\ WHU - Otto Beisheim School of Management \\ Burgplatz 2, 56179 Vallendar, Germany \\ achim.czerny@whu.edu
}

February 2, 2012

\begin{abstract}
This paper analyzes a congested airport that provides aeronautical services to airlines and concessions to retailers and car rental companies. The sum of retail demands inside and outside the airport area is fixed, while an increase of the passenger quantity increases car rental demand. It is shown that an increase of the per passenger retail profit can reduce the private aeronautical charge and the private car rental charge. By contrast, the effect of car rentals on the private aeronautical charge is ambiguous. The welfare-optimal passenger number and aeronautical charge are both independent of retail profit.
\end{abstract}

JEL Classification: D42, D62, L93, R41.

Keywords: Privatization, congestion, concessions, retail services, car rentals.

*I thank Felix Höffler, Peter Welzel, participants of the "X. Symposium zur ökonomischen Analyse der Unternehmung" of the German Economic Association of Business Administration, and especially Anming Zhang for helpful comments. 


\section{Introduction}

A growing number of airports are fully or partially privatized, and airport privatization is almost always accompanied by some form of price regulation. This is because airports are assumed to possess monopolistic market power in the area of aeronautical services, which includes the supply of runway, terminal, and parking capacity for aircraft. ${ }^{1}$ There are specific characteristics of airports that have the potential to reduce the benefits of regulation. First, many airports are scarce in runway and terminal capacity, which leads to congestion; in this situation, an increase of the aeronautical charge limits the demand for airport capacity and delays. Second, airport business areas comprise aeronautical and commercial business areas, where the latter include retailing, advertising, car rentals, car parking and land rents. Since a reduction of the aeronautical charge can increase passenger numbers and concession revenues, this may reduce the private airport operator's incentive to charge an excessively high aeronautical charge from the social viewpoint. Today, the share of revenues from commercial services among airports worldwide has reached an average level of roughly $50 \%$ (ACI 2008). ${ }^{2}$

Commercial airport services can be grouped into two types. Consider retail services and car rentals as examples. The overall demand for retail services (total demand for retail services inside and outside the airport area) may be independent of traveling activities. For example, the consumption of food and beverages is not likely to depend much on whether individuals fly or not fly because individuals will also eat and drink when they stay at home. This is different in the case of car rentals, where the demand is directly linked to traveling activities. Retail services and car rentals may also represent other commercial service areas such as car parking or advertising. Moreover, empirical studies found that shopping can depend on traveling activities to some extent, which means that part of the retail services can also be grouped into the "car-rental category". Based on a sample of passengers at Belgian airports, Geuens et al. (2004) find that airport shopping can elicit travel-related needs such as airport-atmosphere-related and airport infrastructure-related motivations. Further evidence for airport-specific shopping behavior, for example, related to the spending of remaining foreign currencies or bridging waiting times is provided by Brown (1992), Timothy and Butler (1995), Rowley and Slack (1999), Dube and Menon (2000) and Sulzmaier (2001). Moreover, van Dender (2007) found empirically that the per passenger concession revenues are declining in the passenger quantity. This would be consistent with the concept that concession prices can change passenger demand. In the light of this discussion of concession types, the key contribution of this paper is to propose a framework that can be used to investigate private versus welfare-optimal airport behavior when a part of the overall demand for concession services is fixed. This analysis can contribute to the understanding of 1) the relationship between aeronautical and commercial airport business areas and 2) the conflicts of interest between private airports and regulators.

The analysis is in three steps. The model concentrates on "retail services" in a first step (retail services are in inverted commas because not all airport retail services may belong to this modeling category). Fixed demand and two parameters are used to capture the effects of a demand for concession services that is independent of traveling activities. One parameter, which is called the profit parameter, determines the airport's per passenger profit from retail services. The second parameter, which is called the surplus parameter, measures whether individuals are better off buying retail services inside or outside the airport area. For example, airports can have localized monopoly power and charge relatively high prices for food and beverages (that is, individuals are better off buying food and beverages outside the airport area), while prices are relatively low for duty-free goods (that is, individuals are better off buying duty-free goods inside the airport area). ${ }^{3}$ Car rental services are

\footnotetext{
${ }^{1}$ For example, Bel and Fageda (2010) empirically analyze European airports and find that private, unregulated airports charge relatively high prices compared to public or regulated airports.

${ }^{2}$ Forsyth (2004) elaborates on the role of locational rents for commercial airport services. Graham (2009) discusses the importance of commercial revenues to today's airports.

${ }^{3}$ Thompson (2007) finds that about $25 \%$ of airport retail income was generated by duty free sales at UK airports in 2006.
} 
considered in a second step (while it is abstracted away from retail services where the overall demand is independent of traveling activities). Here it is assumed that the overall demand for car rentals depends on traveling activities and that the demand for airport car rentals increases in passenger numbers. Consider a business traveler with a high value of time as an example, and assume that the full price of traveling (including time cost) reaches a prohibitive level so that this passenger demands a package of flights plus car rental. In a final step, an integrated analytical model is considered, which incorporates retail and car rental services. All model variations incorporate a congested airport that provides aeronautical services to airlines and concessions to retailers or, respectively, car rental companies. The rents of concessionaires are completely captured by the airport via take-it-or-leave offers for concessions. ${ }^{4}$ Each model is then used to analyze two scenarios: 1) a private airport that chooses airport charges to maximize airport profit and 2) a public airport that maximizes social welfare (sum of consumer and producer surplus). Airport and airline behavior is modeled as a two-stage game. In the first stage, the airport chooses airport charges. In the second stage, airlines are in Cournot competition.

The main insights are the following. The analysis of retail businesses shows that the private aeronautical charge is excessive from the social viewpoint when retail profits (and car rental profits) are zero, while an increase of the profit parameter reduces the private aeronautical charge. By contrast, the welfare-optimal aeronautical charge is independent of the profit parameter, since the overall retail demand is fixed. The welfare-optimal passenger number is independent of the surplus parameter for the same reason. This implies that an increase of the surplus parameter, which means that the advantage of buying retail services outside the airport area increases, is associated with a reduction of the welfare-optimal aeronautical charge and airfare and vice versa. The analysis of car rentals, shows that the effect of car rentals on the private aeronautical charge can be positive or negative. The intuition is that the existence of car rentals increases passenger demand and exhibits downward pressure on the aeronautical charge at the same time. The total effect of car rentals on the private aeronautical charge is, therefore, ambiguous. The welfare-optimal car rental charge and airfare is equal to social marginal cost in the car rental scenario. In the integrated scenario with retailers and car rentals, retailers can reduce the private aeronautical charge and the private car rental charge. These results are partly consistent with the results derived by other economists.

Starkie (2001 and 2008) provides a graphical analysis and demonstrates that commercial services can reduce the private aeronautical charge. Zhang and Zhang (2003 and 2010), Oum, Zhang and Zhang (2004) find the same relationship but, in addition, they find that, to maximize total surplus, the aeronautical charge should not fully internalize marginal congestion costs to passengers. In their context, this is to increase the surplus generated by commercial services. This result is in contrast to the results presented in this paper, where the welfare-optimal passenger number is unrelated to retail services and airfares must fully internalize congestion cost to passengers in the car-rental scenario. Zhang and Zhang (2003 and 2010) find that the private aeronautical charge is always greater than the total surplus-maximizing charge; this is another result that stands in contrast to the results presented here, where passenger numbers can become excessive from the social viewpoint when the profit parameter is sufficiently high. These authors consider a single, monopolistic commercial airport service; hence, they abstract away from the differences between commercial business areas and their specific market environments, and this is the main reason for the discrepancy between their results and the results derived in this paper. In particular, they do not take into account that 1) the overall demand for commercial services may be independent of traveling and 2) commercial services can change passenger demand. Czerny (2006) considers an analytical model of an uncongested airport that provides aeronautical and commercial services. He finds that commercial services increase the private aeronautical charge, as is consistent with the results presented in this paper. However, he

\footnotetext{
${ }^{4}$ This assumption is not entirely realistic because concessionaires may earn some rents in practice; however, it simplifies the strategic relationship between the airport and concessionaires and should not effect the main insights obtained in this paper.
} 
abstracts away from retail services and, therefore, underestimates the potential of commercial services to reduce the private aeronautical charge. The relationship between airline market shares and the internalization of marginal congestion costs has been investigated by Daniel (1995), Brueckner (2002), Pels and Verhoef (2004), Basso and Zhang (2008), Brueckner and van Dender (2008) and Czerny and Zhang (2011 and 2011a).

The paper is organized as follows. Section 2 presents the model of a congested airport that offers aeronautical services and concessions to retailers. Section 3 analyzes equilibrium airline behavior and private versus welfare-optimal airport behavior in a context where retail services exist. Retail services are replaced by car rental services in Section 4. Section analyzes an analytical example that incorporates retail services and car rentals. Section 6 provides concluding remarks and a discussion of the results.

\section{The Model}

The supply side is described first. There is an airport that provides aeronautical services to airlines and concessions and shopping areas to commercial service providers. In the area of aeronautical services, the airport is a monopoly provider and charges a price $\tau$ per passenger to airlines, while per passenger costs are $c_{1} \geq 0$. The passenger quantity is denoted by $q_{1}$, which gives airport profits $\left(\tau-c_{1}\right) q_{1}$.

In the area of commercial services, the airport is a monopoly provider of concessions and captures all rents via take-it-or-leave-it offers to concessionaires. Assume that only retailers are provided with concessions, where airport retail services incorporate the supply of food and beverages, cigarettes, alcohol, electrical appliances and clothing and footwear (Thompson 2007). ${ }^{5}$ The overall retail demand is fixed and, thus, independent of traveling activities because individuals demand retail services outside the airport (e.g. nearby their home area) when they stay at home and at the airport when they decide to travel. ${ }^{6}$ The costs of retailers inside and outside the airport area are the same (besides concession costs). Denote the individual's consumer surplus from the consumption of retail services in the home area by $\phi^{h} \geq 0$ and the respective surplus from consumption at the airport by $\phi^{a} \geq 0$. Moreover, denote the difference between surpluses by $\Phi \equiv \phi^{a}-\phi^{h}$, which is called the "surplus parameter". The sign of the surplus parameter $\Phi$ can be positive or negative. If it is positive, individuals are better off buying retail services outside the airport, while they are better off buying retail services at the airport if it is negative. The reason for this ambiguity is based on the observation that airport retail prices can be high or low relative to prices charged outside the airport area. For example, airport retailers can have localized monopoly power and charge prices that are above the competitive level outside the airport area, e.g., for food and beverages. On the other hand, duty free prices can be relatively low because localized monopoly power is typically less relevant there. ${ }^{7}$ Denote the per passenger profit from airport retail services by $\kappa \geq 0$, which is called the "profit parameter". Letting " $R$ " indicate the scenario with retail services (and without car rentals), total airport profit is

$$
\Pi^{R}=\left(\tau+\kappa-c_{1}\right) q_{1}
$$

Runway and terminal capacity is limited so that traveling leads to congestion, which raises the costs of passengers and airlines. Denote average congestion costs by $\Gamma\left(q_{1}\right) \geq 0$ with $\Gamma^{\prime}>0$ and $\Gamma^{\prime \prime} \geq 0$. The airline market is oligopolistic with $n \geq 1$ homogenous airlines in Cournot competition,

\footnotetext{
${ }^{5}$ Retailers will be replaced by car rental companies in Section 4 . The joint supply of retail and car rental services is analyzed in Section 5.

${ }^{6}$ In reality, the overall consumption of retail services may not be totally independent of traveling activities. However, this paper concentrates on the observation that a part of the surplus generated at airports would also exist when individuals would not travel.

${ }^{7}$ Thompson (2007) found that about $25 \%$ of airport retail income was generated by duty free sales at UK airports in 2006 .
} 
and airline passenger numbers are denoted by $q_{1 i} \geq 0$ with $i=1, \ldots, n$ and $\sum_{i} q_{1 i}=q_{1}$. Airline costs, besides the aeronautical charge $\tau$ and congestion costs, are normalized to zero. Let $p_{1}$ denote the airfare and $\alpha \in[0,1]$ the share of congestion costs borne by airlines.

Turning to the demand side, travel benefits are denoted by $B^{R}\left(q_{1}\right)$ with $\left(B^{R}\right)^{\prime \prime}<0$ (where " $R$ " indicates the retail scenario), and average congestion costs borne by passengers are $(1-\alpha) \Gamma$. In demand equilibrium $\left(B^{R}\right)^{\prime}=p_{1}+(1-\alpha) \Gamma+\Phi$, where the sum of the first two terms on the right-hand side (RHS) is the "full price" of flying, while the third term is the benefit (or disbenefit) of buying retail services outside the airport area. Rearranging gives the inverse airline-passenger demand $P_{1}^{R}\left(q_{1}\right)=\left(B^{R}\right)^{\prime}-(1-\alpha) \Gamma-\Phi$, which is independent of the profit parameter $\kappa$. Then, airline profits are

$$
\pi_{i}^{R}=\left(P_{1}^{R}-\tau-\Gamma\right) q_{1 i}
$$

for $i=1, \ldots, n$. Observe that airline profits are independent of $\alpha$ and, thus, the Cournot outcome is independent of $\alpha$ as well. This shows that the effect of congestion on passengers and carriers only depends on the total level of congestion costs but is independent of the distribution between passengers and carriers. Without loss of generality, it is assumed that congestion costs are fully borne by airlines $(\alpha=1)$.

The consumer surplus associated with traveling is

$$
C S^{R}=\int_{0}^{q_{1}} P_{1}^{R}(y) d y-q_{1} P_{1}^{R},
$$

which incorporates the reduction of consumer surplus from demanding retail services inside the airport area given by $\Phi q_{1}$. Before the social objective function is determined, note that traveling does not generate welfare in the retail area. This is because retail demand is fixed and, thus, independent of traveling and costs of retailers are the same. For example, if $\Phi>0$, there is no welfare loss from shopping inside the airport area. This is because the high value of the surplus parameter can be associated with a high profit of retailers inside the airport area relative to retailers outside the airport area. The social objective function is

$$
W^{R}=C S^{R}+\Pi^{R}+\sum_{i} \pi_{i}^{R}+(\Phi-\kappa) q_{1} .
$$

The third term on the RHS corrects the effect of the surplus and the profit parameter from the total welfare perspective, which incorporates the welfare effect of retailers that are located outside the airport. Altogether, welfare is independent of the profit and the surplus parameter.

Airport and airline behavior is modeled as a two-stage game. In the first stage, the airport chooses $\tau$ to maximize $\Pi^{R}$ in the case of a private airport or $W^{R}$ in the case of welfare maximization. In the second stage, airlines are in Cournot competition and simultaneously choose $q_{1 i}$ to maximize $\pi_{i}^{R}$. The game is solved by backward induction.

\section{Retail Services}

Assume that airline behavior is determined by the first-order conditions $\partial \pi_{i} / \partial q_{1 i}=0$ for $i=1, \ldots, n$, which implies

$$
P_{1}^{R}-\tau-\Gamma+q_{i 1}\left(P_{1}^{R}\right)^{\prime}-q_{i 1} \Gamma^{\prime}=0
$$

for $i=1, \ldots, n$. The following (standard) assumption ensures that airline quantities are strategic substitutes and that each firm's profit maximization problem is strictly concave:

Assumption 1 For any $q_{1}>0,\left(P_{1}^{R}\right)^{\prime}+q_{1}\left(P_{1}^{R}\right)^{\prime \prime}<0$. 
Simultaneously solving the first-order conditions leads to the equilibrium behavior depending on $\tau, q_{i 1}^{R}(\tau)$. The relationship between passengers numbers and airline costs as well as the relationship between passenger numbers and the surplus parameter is negative:

Lemma 1 If the aeronautical charge $\tau$ or the surplus parameter $\Phi$ increases, this reduces the total quantity of passengers in equilibrium, that is, $\partial q_{i 1}^{R} / \partial z<0$ for $z=\tau, \Phi$.

Proof See Appendix A.

Private airport behavior is considered first. Substituting $n q_{i 1}^{R}$ for $q_{1}$ in the airport profit in (1) gives the airport profit depending on $\tau$. Assume that the private aeronautical charge, which is indicated by superscript " $R, P$ ", is determined by the first-order condition $d \Pi^{R} / d \tau=0$. This implies

$$
\left(\tau^{R, P}+\kappa-c_{1}\right) \frac{\partial q_{1}^{R}}{\partial \tau}+q_{1}^{R}=0 .
$$

To ensure that the second order condition is satisfied and a unique solution to the private airport's maximization exists, airport profit satisfies:

Assumption 2 For any $q_{1}>0, d^{2} \Pi^{R} / d \tau^{2}<0$.

Since $\partial^{2} \Pi^{R} / \partial \tau \partial \kappa=-\partial q_{1}^{R} / \partial \tau>0$ by Lemma 1, Assumption 2 implies:

Proposition 1 An increase in per passenger retail profits reduces the private aeronautical charge, that is, $\partial \tau^{R, P} / \partial \kappa<0$.

The intuition is that private airports have an incentive to reduce aeronautical charges to increase concession revenues, which reproduces the results derived by Starkie (2001 and 2008), Zhang and Zhang (2003 and 2010), and Oum, Zhang and Zhang (2004). Economists often abstract away from the effect of concession services on passenger demand. For example, Zhang and Zhang (2003) assume that booking is independent of airport retail prices because booking activities and the purchase of airport retail services are separated in time, which can be realistic for relatively small absolute values of the retail parameter. The model proposed here is close to their approach for $\Phi \rightarrow 0$, while one important difference remains, which is the fixed overall retail demand.

The relationship between the surplus parameter and the private aeronautical charge is difficult to predict because the sign of $\partial^{2} \Pi^{R} / \partial \tau \partial \Phi$ can be positive or negative in principal. The analytical example based on linear functional forms in Section 5, suggests that $\partial^{2} \Pi^{R} / \partial \tau \partial \Phi<0$ and, thus, that an increase of the surplus parameter reduces the private aeronautical charge. This is intuitive, since an increase of the surplus parameter reduces the total passenger quantity when the aeronautical charge is given.

Turning to the behavior of a public airport, the following assumptions are imposed on the welfare function in (4):

Assumption 3 There is a unique and strictly positive welfare maximizing passenger quantity $q_{1}^{R, *}$.

The social objective function depending on $\tau$ can be obtained by substituting $q_{1 i}^{R}$ for $q_{1 i}$ and $q_{1}^{R}$ for $q_{1}$ in the social objective function in (4). Assume that the public aeronautical charge denoted by $\tau^{R, G}$ is determined by the first-order condition $d W^{R} / d \tau=0$. The public airport behavior is then determined by

$$
\frac{\partial W^{R}}{\partial q_{1}} \frac{\partial q_{1}^{R}}{\partial \tau}=\left(P_{1}^{R}-c_{1}-\Gamma+\Phi-q_{1}^{R} \Gamma^{\prime}\right) \frac{\partial q_{1}^{R}}{\partial \tau}=0 .
$$

Denote the welfare-optimal passenger airfare by $P_{1}^{R, *}$. This leads to: 
Proposition 2 (i) The welfare-optimal aeronautical charge $\tau^{R, G}$ yields the welfare-optimal passenger quantity $q_{1}^{R, *}$. (ii) An increase of the surplus parameter reduces $\tau^{R, G}$, that is, $\partial \tau^{R, G} / \partial \Phi<0$. (iii) The welfare-optimal airfare $P_{1}^{R, *}$ is equal to the social marginal passenger cost only if the surplus parameter is equal to zero, while the welfare-optimal airfare is below (exceeds) social marginal passenger cost if the surplus parameter is positive (negative).

Proof See Appendix B.

The intuition for parts ii and iii is the following: An increase of the surplus parameter implies that traveling is more costly for passengers. On the other hand, the social benefits of traveling are independent of the surplus parameter because the overall retail demand (sum of retail demand in- and outside the airport area) is fixed. Thus, to correct for the negative demand effect of an increase of the surplus parameter, the airfare must be reduced by reducing the aeronautical airport charge. One can further show that $\tau^{R, G}$ incorporates carrier subsidies and a congestion charge both depending on carrier market power. The effect of carrier market power on subsidies and the self-internalization of congestion effects has been analyzed by, amongst others, Daniel (1995), Brueckner (2001), Pels and Verhoef (2004), Zhang and Zhang (2006), Basso (2008), Brueckner and van Dender (2008) and Czerny and Zhang (2011 and 2011a). ${ }^{8}$

Zhang and Zhang (2003 and 2010) investigate a congested airport that is a monopoly provider of aeronautical services and commercial services. They assume that traveling decisions are independent of commercial airport services, while the overall consumption of commercial services depends on traveling activities. These assumptions are different from the context employed in this paper. The implications are also different because Zhang and Zhang find that the welfare-optimal airfare should not fully internalize marginal congestion costs to passengers in order to increase the surplus generated by commercial services. This is in contrast to Proposition 2, which shows that the welfare-optimal airfare can be equal or even greater than marginal passenger cost, which depends on the value of the surplus parameter.

A natural question is whether the presence of retail services can provide the right incentives from the social viewpoint so that private airport behavior yields the welfare-optimal outcome. The following proposition shows that this can be the case:

Proposition 3 There is a strictly positive value of the profit parameter $\kappa$ that reaches the welfareoptimal outcome under private airport ownership when $\Phi \geq 0$.

Proof See Appendix C.

Private airport behavior can, thus, yield or come close to the welfare-optimal outcome when airport retail services exist. This is because an increase of the profit parameter, reduces the private aeronautical charge (Proposition 2), which can be beneficial from the social viewpoint when passengers would better be served by retailers in their home area $(\Phi \geq 0)$. This is consistent with the graphical analysis of Starkie (2001 and 2008).

Since the value of the profit parameter must be strictly positive to reach the welfare optimal outcome when the surplus parameter is positive and the private aeronautical charge is decreasing in the profit parameter by Proposition (1), it follows:

Corollary 1 The private aeronautical charge is excessive from the social viewpoint $\left(\tau^{R, P}>\tau^{R, G}\right)$ when $\kappa=0$ and $\Phi \geq 0$.

\footnotetext{
${ }^{8}$ The empirical results on the relationship between market shares and congestion provided by Brueckner (2002), Mayer and Sinai (2003), Daniel and Harback (2008), and Morrison and Winston (2007) are controversial, however. A lack of self-internalization could occur when a Stackelberg airline interacts with a competitive fringe (Daniel (1995) and Brueckner and van Dender (2008)). Variations in the passengers' values of time can also lead to an outcome that seems inconsistent with self-internalization (Czerny and Zhang (2011 and 2011a)).
} 
It is the typical understanding that private aeronautical charges are excessive from the social viewpoint (e.g. Zhang and Zhang 2003 and Basso 2008). The current setting may lead to too low aeronautical charges and excessive congestion from the social viewpoint when $\kappa$ is sufficiently high or $\Phi<0$, however. This is because the private airport's incentive to reduce the aeronautical charge in order to increase retail profits is too high or, respectively, the passengers' incentives to shop inside the airport area are too high.

\section{Car Rentals}

\subsection{The model}

In this part, car rental services are considered, while it is abstracted away from retail services. ${ }^{9}$ Assume that the airport provides concessions to (homogeneous) car rental companies, and that, as part of the concessions, the airport determines the car rental charge $p_{2}$. Concessions are such that the airport captures all rents from car rentals, and marginal car rental costs $c_{2}$ are constant.

Car rentals are essential for certain passengers, especially for business passengers with a high value of time, to circumvent the use of public transport services and limit total travel time, and these passengers may wish to rent cars directly inside the airport area. Therefore, the extreme assumption that there is no competition between car rental companies in- and outside the airport area is imposed. An important difference between car rentals and retailing is that the overall demand for car rentals (sum of car rental demand inside and outside the airport area) depends on traveling, while the overall retail demand is assumed to be fixed. This is because car rentals are normally not needed when individuals decide not to travel.

In the current scenario with car rentals (which is indicated by superscript " $C$ "), passenger benefits $B^{C}$ depend on the number of travelers, $q_{1}$, and the number of car rentals $q_{2}$. The inverse passenger demand then is $\partial B^{C} / \partial q_{1}$ and the inverse demand for car rentals is $\partial B^{C} / \partial q_{2}$. Assume that solving $p_{2}=\partial B^{C} / \partial q_{2}$ for $q_{2}$ yields a unique solution for the car rental demand $D_{2}^{C}$, which depends on $q_{1}$ and $p_{2}$. Then, substituting $q_{2}$ by $D_{2}^{C}$ in the inverse passenger demand leads to the inverse passenger demand depending on the passenger number and the car rental charge $P_{1}^{C}\left(q_{1}, p_{2}\right)$.

To model the complementarity between aeronautical and car rental services, the following assumptions are imposed on demands:

Assumption 4 (i) For any $q_{1}, D_{2}>0, \partial D_{2}^{C} / \partial p_{2}<0$ and $\partial P_{1}^{C} / \partial q_{1}<0$.

(ii) An increase in the number of passengers increases the car rental demand at a declining rate, that is, $\partial D_{2}^{C} / \partial q_{1}>0$ and $\partial^{2} D_{2}^{C} / \partial q_{1}^{2} \leq 0$.

(iii) For any $q_{1}, D_{2}>0$, a reduced price for car rentals increases the inverse passenger demand, that is, $\partial P_{1}^{C} / \partial p_{2}<0$.

(iv) An increase of the passenger number reduces the effect of a change of the car rental charge on inverse passenger demand, that is, $\partial^{2} P_{1}^{C} / \partial p_{2} \partial q_{1} \leq 0$.

(v) Only passengers demand car rental services inside the airport area (customers do not travel from the outside airport area to the airport to rent a car given that they do not intend to travel), that is, $D_{2}^{C}\left(0, p_{2}\right)=0$ for all $p_{2} \in \mathbb{R}$.

The relationships in i and ii are natural. To illustrate the economic rationale behind the relationship in iii, consider a business traveler who achieves profit $\phi>p_{1}$ by flying and renting a car. Without car rentals, the business traveler uses public transport services, which increases total travel costs by $\theta>\phi-p_{1}$. The business traveler flies only if $p_{2}$ is low enough in this situation. iv ensures that an increase in the car rental charge reduces equilibrium passenger numbers. The intuition is that passengers with a high willingness to pay for traveling are more likely to rent a car (think of business

\footnotetext{
${ }^{9}$ The supply of car rentals may also represent car parkings, which are of great importance for many airports as well.
} 
passengers versus leisure passengers). ${ }^{10}$ Finally, the simplifying assumption in $\mathrm{v}$ helps to concentrate on the complementary relationship between the passenger demand and the demand for commercial airport services.

In this modified context, airport profit becomes

$$
\Pi^{C}\left(\tau, p_{2}\right)=\left(\tau-c_{1}\right) q_{1}+\left(p_{2}-c_{2}\right) D_{2}^{C}\left(q_{1}, p_{2}\right) .
$$

Airline profits $\pi_{i}^{C}$ are obtained by substituting $P_{1}^{R}$ for $P_{1}^{C}$ in (2), and consumer surplus becomes

$$
\begin{aligned}
C S^{C} & =B^{C}-P_{1}^{C} q_{1}-p_{2} D_{2}^{C} \\
& =\oint_{\left(0, p_{2}\right)}^{\left(q_{1}, \infty\right)}\left[P_{1}^{C}\left(x_{1}, x_{2}\right) d x_{i}+D_{2}^{C}\left(x_{1}, x_{2}\right) d x_{j}\right]-P_{1}^{C} q_{1}
\end{aligned}
$$

with $j \neq i$. Since income effects are zero, the integrability condition is satisfied (Crew and Kleindorfer, 1979); therefore, the solution of the line integral in (10) is independent of the particular path along which integration is taken. One way to calculate consumer surplus is

$$
C S^{C}=\int_{0}^{q_{1}} P_{1}^{C}\left(x_{1}, p_{2}\right) d x_{1}-P_{1}^{C} q_{1},
$$

since $D_{2}^{C}\left(0, p_{2}\right)=0$ for all $p_{2} \in \mathbb{R}$ by Assumption 4 . The social objective function becomes

$$
\begin{gathered}
W^{C}=C S^{C}+\Pi^{C}+\sum_{i} \pi_{i}^{C} \\
=\int_{0}^{q_{1}} P_{1}^{C}\left(x_{1}, p_{2}\right) d x_{1}-\left(c_{1}+\Gamma\right) q_{1}+\left(p_{2}-c_{2}\right) D_{2}^{C} .
\end{gathered}
$$

Observe that commercial services are part of $W^{C}$, which stands in contrast to $W^{R}$. This is because the overall car rental demand depends on traveling.

\subsection{Private airport}

Equilibrium airline behavior is considered first. Assume that this behavior is determined by the firstorder condition $\partial \pi_{i}^{C} / \partial q_{1 i}=0$ for $i=1, \ldots, n$. To ensure that passenger quantities are strategic substitutes, it is assumed that $\partial P_{1}^{C} / \partial q_{1}+q_{1} \partial^{2} P_{1}^{C} / \partial q_{1}^{2}<0$, which is analog to Assumption 1. The relationships between the aeronautical charge or the car rental charge and equilibrium passenger numbers are intuitiv:

Lemma 2 An increase of the aeronautical charge or the car rental charge both reduces equilibrium passenger numbers, that is, $\partial q_{1}^{C} / \partial z<0$ for $z=\tau, p_{2}$.

Proof See Appendix D.

Turning to stage one and substituting $q_{1}^{C}$ for $q_{1}$ in $\Pi^{C}$ gives the airport profit depending on $\tau$ and $p_{2}$. Assume that the private airport behavior is determined by the first-order conditions $\partial \Pi^{C} / \partial \tau=0$ and $\partial \Pi^{C} / \partial p_{2}=0$, which implies

$$
q_{1}^{C}+\left(\tau^{C, P}-c_{1}\right) \frac{\partial q_{1}^{C}}{\partial \tau}+\left(p_{2}-c_{2}\right) \frac{\partial q_{2}^{C}}{\partial \tau}=0
$$

\footnotetext{
${ }^{10}$ Pels et al. (2003) find that business passengers are more likely to use a rental car relative to leisure passengers.
} 
and

$$
\left(\tau-c_{1}\right) \frac{\partial q_{1}^{C}}{\partial p_{2}}+q_{2}^{C}+\left(p_{2}^{C, P}-c_{2}\right) \frac{\partial q_{2}^{C}}{\partial p_{2}}=0,
$$

where $C, P$ indicates the scenario with a private airport and car rental services. To ensure that a unique solution exists for private and public airports, assume that:

Assumption 5 Airport profit $\Pi^{C}$ and welfare $W^{C}$ are both quasiconcave in $\tau$ and $p_{2}$.

Consider the effect of car rentals on the aeronautical charge first. A useful benchmark for the aeronautical charge in a context with car rentals is the private aeronautical charge that would be chosen if car rentals would not exist $\left(p_{2} \rightarrow \infty\right.$ and $\left.D_{2}=0\right)$. In this situation, the third term on the RHS of (13) vanishes; hence, the private airport follows the standard rule where the mark-up on $c_{1}$ is inversely related to the price elasticity of airline demand for aeronautical services. Suppose that the profit margin of car rentals is positive $\left(p_{2}-c_{2} \geq 0\right)$ with $p_{2}<\infty$. In this situation, there are two opposing effects and car rentals can have a positive or a negative effect on the private aeronautical charge. First, the private aeronautical charge should be increased because car rentals increase passenger demand relative to a situation without car rentals. Second, the aeronautical charge should be reduced, to take advantage of the demand complementarity between the demands for aeronautical and car rental services. The overall effect of car rentals on the aeronautical charge can, therefore, be positive or negative. More specifically, letting $\tau^{P}$ denote the private aeronautical charge in the absence of concession revenues, $\tau^{C, P} \geq \tau^{P}$ when

$$
p_{2} \leq c_{2}-\left(q_{1}^{C}+\left(\tau^{P}-c_{1}\right) \frac{\partial q_{1}^{C}}{\partial \tau}\right) \frac{\partial \tau}{\partial q_{2}^{C}},
$$

which follows from the first-order condition in (13) and Assumption 5. Moreover, if the profit margin of car rentals is negative $\left(p_{2}-c_{2}<0\right)$, the effect of car rentals on the aeronautical charge is clear-cut and positive. This is because car rentals increase the airline demand for aeronautical services and further because a greater aeronautical charge is used to reduce losses in the car rental business area.

To illustrate the effect of aeronautical services on the car rental charge implied by the first-order condition in (14) and Assumption 5, $\tau=c_{1}$ is used as a benchmark. Then, if the profit margin of aeronautical services is positive (negative), aeronautical services increase (decrease) the private car rental charge due to the complementarity of demands. In the current scenario without retailing, a situation where the aeronautical charge and the car rental charge are below marginal costs $\left(\tau-c_{1}<0\right.$ and $\left.p_{2}-c_{2}<0\right)$ cannot be optimal for a private airport. To summarize:

Proposition 4 (i) Car rentals can increase or reduce the private aeronautical charge relative to a situation where car rentals not exist, and (ii) a private operator may offer aeronautical services or car rental services for a price below marginal cost.

Part i stands in contrast to the notion of economists, who find a strict negative relationship between the private aeronautical charge and commercial airport services (for example, Starkie 2001 and 2008 and Zhang and Zhang 2003 and 2010). The reason for this discrepancy is that these economists abstract away from the possibility that the supply of commercial services can change passenger demand. Czerny (2006) elaborates on an uncongested airport that provides aeronautical and commercial services where the overall demand for commercial services depends on traveling activities. He finds a specific constellation where commercial airport services increase the private aeronautical charge relative to a scenario where commercial services would not exist, which is consistent with Proposition 4. The results described in part ii are consistent with the results derived by Tirole (1988), who considered a multi-product monopoly and found that, in the case of complements, goods may be sold below marginal cost. ${ }^{11}$

\footnotetext{
${ }^{11}$ Goods are considered as complements when an increase in the supply of one good increases the demand for the other good or a reduction of one good's price increases the other good's demand.
} 


\subsection{Public airport}

To investigate the behavior of a public airport, substitute $q_{1}^{C}$ for $q_{1}$ in (12), which gives the social objective function depending on $\tau$ and $p_{2}$. Assume that the public airport behavior is determined by the first-order conditions $\partial W^{C} / \partial \tau=\partial W^{C} / \partial q_{1} \cdot \partial q_{1}^{C} / \tau=0$ and $\partial W^{C} / \partial p_{2}=0$, which gives

$$
\left(P_{1}^{C}-\left(c_{1}+\Gamma+\Gamma^{\prime} q_{1}^{C}\right)+\left(p_{2}-c_{2}\right) \frac{\partial D_{2}^{C}}{\partial q_{1}}\right) \frac{\partial q_{1}^{C}}{\partial \tau}=0
$$

and

$$
\int_{0}^{q_{1}^{C}} \frac{\partial P_{1}^{C}}{\partial p_{2}} d x_{1}+D_{2}^{C}+\left(p_{2}^{C, G}-c_{2}\right) \frac{\partial D_{2}^{C}}{\partial p_{2}}=0,
$$

where " $C, G$ " indicates the scenario with a public airport and car rental services. The third term on the left-hand side (LHS) of first-order condition in (16) shows that the welfare-optimal passenger quantity determined by $\partial W^{C} / \partial q_{1}=0$ depends on the value of the car rental charge $p_{2}$ relative to the car rental cost $c_{2}$. On the other hand, the first term on the LHS of the first-order condition in (17) shows that the welfare-optimal car rental charge depends on the impact of the car rental charge on passenger demand. Letting " $C, *$ " indicate the welfare-optimal solutions for passenger numbers and airfares, these first-order conditions imply:

Proposition 5 (i) The welfare-optimal aeronautical charge $\tau^{C, G}$ yields the welfare-optimal passenger quantity $q_{1}^{C, *}$. (ii) The welfare-optimal car rental charge $p_{2}^{C, G}$ is equal to marginal cost $c_{2}$. (iii) The welfare-optimal airfare $P_{1}^{C, *}$ is equal to the social marginal passenger cost.

Proof See Appendix E.

Part $\mathrm{i}$ also holds in the case of retail services, while parts ii and iii reproduce the standard result that marginal cost pricing is welfare-optimal. Note that part iii stands in contrast to the scenario with retail services, where the welfare-optimal airfare depends on the surplus parameter. These results are also in contrast to the results derived by Zhang and Zhang (2003 and 2010), who found that the welfare-optimal airfare is smaller than social marginal passenger cost when passenger demand is independent of commercial airport services and commercial services increase welfare.

For the relationship between private and welfare-optimal airport behavior it holds:

Proposition 6 The private aeronautical charge is excessive from the social viewpoint $\left(\tau^{C, P}>\tau^{C, G}\right)$ when $p_{2}=c_{2}$.

Proof See Appendix F.

This is, again, consistent with the understanding that private aeronautical charges can be excessive from the social viewpoint. Since the welfare-optimal car rental charge equals marginal car rental cost, this proposition directly implies:

Corollary 2 In the scenario with a congested airport that provides aeronautical services to airlines and concessions to car rental companies, the welfare-optimal outcome is never reached under private airport ownership.

Constellations where private airport behavior reproduces or comes close to the welfare-optimal outcome can exist in the integrated scenario where both car rentals and retail services exist. There are two effects that can improve the welfare implications of private airport behavior from the social viewpoint: First, the welfare-optimal airfare can be greater than social marginal cost when the surplus parameter is negative. Second, an increase of the profit parameter reduces the private aeronautical charge. The analytical example below shows that the private car rental charge can also be reduced by the profit parameter. 


\section{Analytical Example}

This section develops an integrated analytical model to analyze the interdependence between aeronautical, retail and car rental businesses and to derive the relationship between private airport behavior and carrier market power. This model is based on a model version employed by Czerny (2006). There is a set of individuals with mass one, where every individual flies at most once and buys at most one unit of car rentals. The individual benefit of flying is $V_{1} \in[0,1]$, and the individual benefit of car rentals is $V_{2} \in[0,1]$. Individuals are uniformly and independently distributed over the $V_{1}-V_{2}$-space. For simplicity, the airport's marginal passenger cost are zero $\left(c_{1}=0\right)$, car rental cost are $c_{2}=1 / 10$ and average congestion cost $\Gamma$ is determined by the passenger quantity, that is, $\Gamma=q_{1}$. Appendix $G$ provides more details on the demand specifications and consumer surplus.

The analytical results concentrate on the case where $\left(p_{1}+\Phi\right)+p_{2}>1$ and $\left(p_{1}+\Phi\right), p_{2}<1$. Under these conditions, the welfare-optimal airfare, car rental charge and aeronautical charge become

$$
p_{1}^{*}=\frac{2}{3}-\Phi, p_{2}^{*}=\frac{1}{10} \text { and } \tau^{*}=\frac{281}{600}-\frac{281}{300 n}-\Phi .
$$

The welfare-optimal airfare and the welfare-optimal car rental charge are equal to the social marginal costs (as suggested by Proposition 5) and independent of the carrier number $n$, surplus parameter $\Phi$ and profit parameter $\kappa$. The welfare-optimal aeronautical charge is also independent of $\kappa$, while it is increasing in the carrier number $n$ and decreasing in the surplus parameter $\Phi$. The positive relationship between the carrier number and the welfare-optimal aeronautical charge exists because carrier competition reduces the need to subsidize carriers in order to reach the welfare-optimal passenger number. The negative relationship between the surplus parameter and the welfare-optimal aeronautical charge corrects for the disbenefit or, respectively, benefit of shopping inside the airport area relative to shopping outside the airport area (this example implies $\partial^{2} \Pi / \partial \tau \partial \Phi=-n /(2(1+n))<0$ ).

Figure 1 displays private airport behavior depending on $\kappa \in[0,1.1]$ for $n=6$ (solid lines) and $n=2$ (dashed lines). ${ }^{12}$ Observe that an increase in $\kappa$ increases the incentive to reduce the aeronautical and the car rental charge $\left(\tau^{P}\right.$ and $p_{2}^{P}$ are decreasing in $\left.\kappa\right)$. However, commercial airport services can also increase the private aeronautical charge. More specifically, car rentals increase passenger demand, which can lead to an increase of the private aeronautical charge. To see this, note that the private aeronautical charge is equal to $1 / 2$ when car rentals not exist $\left(p_{2} \rightarrow \infty\right)$. By contrast, Figure 1 shows that $\tau^{P}>1 / 2$ if $\kappa=0$. Moreover, a change from $n=6$ to $n=2$ carriers reduces the private aeronautical charge, while it increases the private car rental charge. This change in airport behavior can be explained by the complementarity between aeronautical and car rental demands: an increase of the car rental charge increases the profit margin in the car rental area, which increases the incentive to reduce the aeronautical charge. Figure 2 displays airfares and marginal passenger cost (the carriers' passenger cost are $q_{1} \Gamma=q_{1}^{2} \Rightarrow \partial\left(q_{1} \Gamma\right) / \partial q_{1}=2 \Gamma$ ) implied by the private airport behavior displayed in Figure 1. This figure shows that private airport behavior can lead to an excessive use of airport infrastructure, since $P_{1}^{P}<2 \Gamma^{P}$ for sufficiently high values of $\kappa$. Moreover, private airport behavior never implies the welfare-optimal solution under the current parameter constellations, since the car rental charge exceeds $c_{2}=1 / 10$ when $\kappa$ is such that $P_{1}^{P}=2 \Gamma^{P}$ is reached.

To illustrate the relationship between the surplus parameter and private airport behavior, Figure 3 displays private airport behavior for $\Phi=0$ (solid lines) and $\Phi=-1 / 10$ (dashed lines). The figure shows that a reduction of the surplus parameter, which means that inside-airport shopping becomes more attractive for passengers, can increase the private aeronautical charge and reduce the car rental charge. This can be explained by demand complementarity, again. Since the reduced value of $\Phi$ is associated with an increase of profit margins in the aeronautical business area, there is an incentive to reduce the car rental charge.

\footnotetext{
${ }^{12}$ The range of the profit parameter ensures that $\left(p_{1}+\Phi\right)+p_{2}>1$.
} 


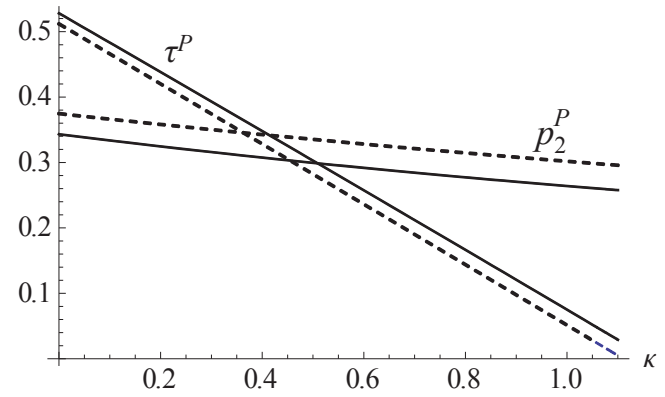

Figure 1: Private airport behavior depending on carrier market power (solid lines $n=6$ and dashed lines $n=2 ; \Phi=0)$.

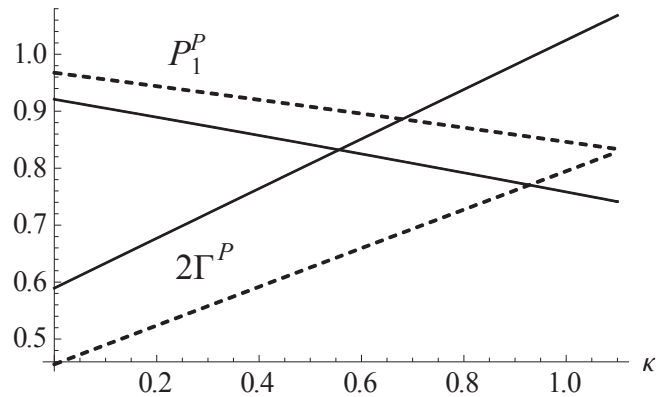

Figure 2: Airfare and the social marginal congestion cost depending on carrier market power (solid lines $n=6$ and dashed lines $n=2 ; \Phi=0$ ).

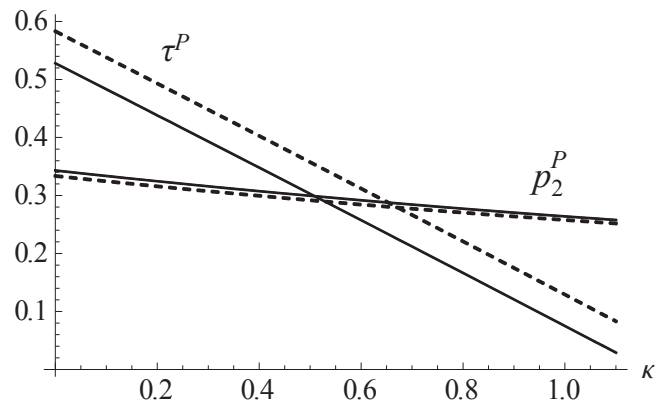

Figure 3: Private airport behavior depending on the surplus parameter $(n=6$; solid lines $\Phi=0$ and dashed lines $\Phi=-1 / 10$ ) 


\section{Conclusions}

In this paper, theoretical models of a congested airport that provides aeronautical services to airlines and concessions to commercial service providers are proposed. These models capture the assumption that the overall retail demand (sum of retail demands inside and outside the airport area) can be independent of traveling activities, while the overall car rental demand depends on traveling (a lower number of passengers is associated with a lower demand for car rental services for a given car rental charge). This paper elaborates on car rental and retail services, while the results also hold for other airport areas such as car parking or advertising. The analysis shows that retail services can reduce the benefits of regulation, while they can also lead to excessive congestion. Car rentals, on the other hand, can increase the benefits of regulation because they can further increase an already excessive aeronautical charge and the private car rental charge can be excessive as well.

There are some aspects that are not covered in this paper but that should be analyzed in the future to obtain a more complete and realistic picture of the relationship between aeronautical and commercial business areas. This includes the consideration of price regulation regimes and capacity choice.

There is the question whether airport price regulation should pursue a single-till or dual-till approach. ${ }^{13}$ The key difference between single-till and dual-till regulation is that with single-till, commercial revenues are used to cover fixed airport costs, which includes runway costs. In comparison, the dual-till approach attributes portions of fixed airport costs to aeronautical and commercial business areas so that cost recovery has to be achieved in both areas separately. In this paper, welfare-optimal behavior can lead to losses in the aeronautical business area, while there are no profits from car rentals to ensure cost recovery. In this case, the implementation of the welfare-optimal outcome is possible under single-till regulation only (or with subsidies, which are usually not available for airports).

Airport capacity can be expanded in reality. To obtain a more complete picture of the conflicts between a private airport and the regulator in a context where commercial revenues exist, it would, therefore, be useful to consider investments. Zhang and Zhang (2003) analyze lumpy airport investments in a growing airport market and find that private airports slow down expansion relative to the expansion path that should be taken under the conditions of total surplus maximization. This result can be different in the setting proposed in this paper, where an increase in retail profits may increase the private incentives to invest into new capacity for aeronautical services, while the welfare-optimal capacity remains unchanged. In a recent paper, Zhang and Zhang (2010) find that private or public airports would over-invest in capacity when airline markets are oligopolistic, however.

Overall, the research provided in this paper is based on a differentiated look at commercial airport services and analyzes the relationships between commercial airport services and passenger demand. The results can, therefore, provide a better picture of airport pricing behavior under public and private airport ownership and the conflicts of interest between private airports and regulators.

\section{A Proof of Lemma 1}

The relationship between individual equilibrium passenger numbers and $z$ is given by

$$
\frac{\partial q_{1 i}^{R}}{\partial z}=\frac{1}{\left(P_{1}^{R}\right)^{\prime}-\Gamma^{\prime}+n\left[\left(P_{1}^{R}\right)^{\prime}+q_{i 1}^{R}\left(P_{1}^{R}\right)^{\prime \prime}-\Gamma^{\prime}-q_{i 1}^{R} \Gamma^{\prime \prime}\right]}
$$

for $z=\tau, \Phi$, which is negative in sign by Assumption 1. By symmetry, it follows that the total passenger quantity is decreasing in $\tau$ and $\Phi$.

\footnotetext{
${ }^{13}$ For a detailed investigation of single-till and dual-till regulation, see Crew and Kleindorfer (2001), Starkie (2001 and 2008), Lu and Pagliari (2004), Oum, Zhang and Zhang (2004), Czerny (2006) and Yang and Zhang (2011).
} 


\section{B Proof of Proposition 2}

To establish part $\mathrm{i}$, recall that Lemma 1 shows that $\partial q_{1}^{R} / \partial \tau<0$. Thus, the first-order condition in (7) is only satisfied if $\partial W^{R} / \partial q_{1}=0$, which implies that public airports yield welfare-optimal passenger quantity.

To establish part ii, recall that an increase of the surplus parameter reduces equilibrium passenger numbers when $\tau$ is given by Lemma 1, while a reduction of $\tau$ increases equilibrium passenger numbers by the same lemma. Thus, an increase of the surplus parameter must be associated with a reduction of $\tau$ to satisfy the first-order condition in (7).

Finally, the first-order condition in (7) implies the first-best airfare

$$
P_{1}^{R, *}=c_{1}+\Gamma+q_{1}^{R, *} \Gamma^{\prime}-\Phi
$$

The first term on the RHS shows the per passenger airport cost, while the second and the third term determines marginal congestion cost. These three terms determine the (total) marginal passenger cost. Moreover, they are independent of the retail parameter in the welfare-optimum. The last term is the negative of the retail parameter. This implies that the welfare-optimal airfare is equal to marginal passenger cost only if $\Phi=0$, while an increase of the retail parameter reduces the welfare-optimal airfare.

\section{Proof of Proposition 3}

To show that this proposition holds true, solve the first-order condition that determines private aeronautical charges in (6) for $\kappa$. Then, solve the first-order condition that determines equilibrium airline behavior in (5) for $\tau$. Substituting $\tau$ yields

$$
\kappa=c_{1}-q_{1}^{R, *} \frac{\partial \tau}{\partial q_{1}^{R}}-\left[P_{1}^{R, *}-\Gamma-\frac{q_{1}^{R, *}}{n}\left(\Gamma^{\prime}-\left(P_{1}^{R, *}\right)^{\prime}\right)\right],
$$

where the RHS of (21) determines the value of $\kappa$ that would imply the first-best aeronautical charge in the private airport scenario. To increase transparency, $\partial q_{1}^{R} / \partial \tau$ is substituted by the RHS of (19). Rearranging then leads to

$$
\begin{array}{r}
\kappa=c_{1}+\left(\Gamma+q_{1}^{R, *} \Gamma^{\prime}\right)-P_{1}^{R, *}-q_{1}^{R, *}\left(P_{1}^{R, *}\right)^{\prime}-\frac{q_{1}^{R, *}}{n}\left[\left(P_{1}^{R, *}\right)^{\prime}-\Gamma^{\prime}\right] \\
-q_{1}^{R, *}\left[\left(P_{1}^{R, *}\right)^{\prime}+\frac{q_{1}^{R, *}}{n}\left(P_{1}^{R, *}\right)^{\prime \prime}-\Gamma^{\prime}-\frac{q_{1}^{R, *}}{n} \Gamma^{\prime \prime}\right]>0 .
\end{array}
$$

The first three terms on the RHS are positive for $\Phi \geq 0$, which follows from the first-best airfare in (20). The remaining terms on the RHS are also positive, since $\left(P_{1}^{R}\right)^{\prime}+q_{1}\left(P_{1}^{R}\right)^{\prime \prime}<0$ by Assumption 1.

\section{Proof of Lemma 2}

Similar to the relation ship in (19) it holds $\partial q_{1}^{C} / \partial \tau<0$. Moreover,

$$
\frac{\partial q_{1}^{C}}{\partial p_{2}}=-\frac{n\left(\frac{\partial P_{1}^{C}}{\partial p_{2}}+q_{1 i}^{C} \frac{\partial^{2} P_{1}^{C}}{\partial q_{1} \partial p_{2}}\right)}{\frac{\partial P_{1}^{C}}{\partial q_{1}}-\Gamma^{\prime}+n\left[\frac{\partial P_{1}^{C}}{\partial q_{1}}+q_{i 1}^{R} \frac{\partial^{2} P_{1}^{C}}{\partial q_{1}^{2}}-\Gamma^{\prime}-q_{1 i}^{C} \Gamma^{\prime \prime}\right]}<0 .
$$




\section{E Proof of Proposition 5}

Since $\partial q_{1}^{C} / \partial \tau<0$ by Lemma $2, \tau^{C, G}$ implies $\partial W^{C} / \partial q_{1}^{C}=0$ by the first-order condition in (16), which establishes part i.

To establish part ii, note that equations (9) and (11) imply

$$
\int_{0}^{q_{1}} P_{1}^{C}\left(x_{1}, p_{2}\right) d x_{1}=B^{C}-p_{2} D_{2}^{C},
$$

where the RHS is an indirect utility. From Roy's identity, it follows that

$$
\int_{0}^{q_{1}} \frac{\partial P_{1}^{C}\left(x_{1}, p_{2}\right)}{\partial p_{2}} d x_{1}=-D_{2}^{C}
$$

in demand equilibrium. Substituting the RHS for $\int_{0}^{q_{1}} \partial P_{1}^{C}\left(x_{1}, p_{2}\right) / \partial p_{2} d x_{1}$ in the first-order condition in (17) together with $\partial D_{2}^{C} / \partial p_{2}<0$ by Assumption 4 leads to $p_{2}^{C, G}=c_{2}$.

To establish part (iii), substitute $c_{2}$ for $p_{2}$ in the first-order condition in (16). It follows that the welfare-optimal airfare $P_{1}^{C, *}$ is equal to the social marginal cost of traveling $c_{1}+\Gamma+\Gamma^{\prime} q_{1}^{C}$.

\section{F Proof of Proposition 6}

Assume that $p_{2}=c_{2}$. Since $\kappa=\Phi=0$ in the car rental scenario, the derivations in Appendix C show that private the aeronautical charge is excessive from the social viewpoint in the car rental scenario.

\section{G Demand Specifications}

The demands are

$$
D_{1}=\left\{\begin{array}{rll}
\max \left\{0,1-\left(p_{1}+\Phi\right)\right\} & \text { if } & p_{2} \geq 1 \\
\max \left\{0, \frac{1}{2}\left(3-2\left(\left(p_{1}+\Phi\right)+p_{2}\right)+p_{2}^{2}\right)\right\} & \text { if } & \left(p_{1}+\Phi\right)+p_{2}>1,\left(p_{1}+\Phi\right), p_{2}<1 \\
1-\left(p_{1}+\Phi\right) p_{2}-\frac{\left(p_{1}+\Phi\right)^{2}}{2} & \text { if } & \left(p_{1}+\Phi\right)+p_{2} \leq 1 \\
\left(2-\left(p_{1}+\Phi\right)-p_{2}\right)^{2} & \text { if } & \left(p_{1}+\Phi\right)>1, p_{2}<1,\left(p_{1}+\Phi\right)+p_{2} \leq 2 .
\end{array}\right.
$$

and

$$
D_{2}=\left\{\begin{array}{rll}
0 & \text { if } & p_{2} \geq 1 \\
\max \left\{0, \frac{1}{2}\left(1-p_{2}\right)\left(3-2\left(p_{1}+\Phi\right)-p_{2}\right)\right\} & \text { if } & \left(p_{1}+\Phi\right)+p_{2}>1,\left(p_{1}+\Phi\right), p_{2}<1 \\
1-p_{2}-\frac{\left(p_{1}+\Phi\right)^{2}}{2} & \text { if } & \left(p_{1}+\Phi\right)+p_{2} \leq 1 \\
\left(2-\left(p_{1}+\Phi\right)-p_{2}\right)^{2} & \text { if } & \left(p_{1}+\Phi\right)>1, p_{2}<1,\left(p_{1}+\Phi\right)+p_{2} \leq 2 .
\end{array}\right.
$$


One way to calculate consumer surplus is the following. First, take $p_{1}$ as given and calculate the consumer surplus generated by car rental services. Second, take $p_{2}=1$ as given and add the consumer surplus generated by aeronautical services:

$$
\begin{aligned}
C S\left(p_{1}, p_{2}\right) & =\oint_{\left(p_{1}, p_{2}\right)}^{(1-\Phi, 1)} \sum_{i} D_{i}\left(x_{1}, x_{2}\right) d x_{i} \\
& =\int_{p_{2}}^{1} D_{2}\left(p_{1}, x_{2}\right) d x_{2}+\int_{p_{1}}^{(1-\Phi)} D_{1}\left(x_{1}, 1\right) d x_{1} .
\end{aligned}
$$

\section{References}

ACI (2008). ACI Airport Economics Survey 2008.

Basso, L. J. (2008). Airport deregulation: Effects on pricing and capacity. International Journal of Industrial Organization, 26:1015-1031.

Basso, L. and Zhang, A. (2008). Sequential peak-load pricing in a vertical setting: The case of airports and airlines. Canadian Journal of Economics, 41:1087-1119.

Bel, G. and Fageda, X. (2010). Privatization, regulation and airport pricing: an empirical analysis for Europe. Journal of Regulatory Economics, 33:142-161.

Brown, G. (1992). Tourism and symbolic consumption. In Johnson, P. and Thomas, B. (Eds.), Choice and demand in tourism. (pp. 51-71). London: Mansell.

Brueckner, J. K. (2002). Airport congestion when carriers have market power. American Economic Review, 92:1357-1375.

Brueckner, J. K. and van Dender, K. (2008). Atomistic congestion tolls at concentrated airports? Seeking a unified view in the internalization debate. Journal of Urban Economics, 64:288-295.

Crew, M. and Kleindorfer, P. (2001). Regulation for privatized airports: Single-till versus multi-till pricing methodologies for Sydney airport. Unpublished.

Crew, M. A. and Kleindorfer, P. R. (1979). Public Utility Economics. St. Martin's Press.

Czerny, A. I. (2006). Price-cap regulation of airports: single-till versus dual-till. Journal of Regulatory Economics, 30:85-97.

Czerny, A. I. and Zhang, A. (2011). Airport congestion pricing and passenger types. Transportation Research Part B: Methodological, 45:595-604.

Czerny, A. I. and Zhang, A. (2011a). Price discrimination, social welfare and congestion pricing. Unpublished.

Daniel, J. I. (1995). Congestion pricing and capacity of large hub airports: A bottleneck model with stochastic queues. Econometrica, 63:327-370.

Daniel, J. I. and Harback, K. T. (2008). (When) Do hub airlines internalize their self-imposed congestion delays? Journal of Urban Economics, 63:583-612.

Dube, L. and Menon, K. (2000). Ensuring greater satisfaction by engineering salesperson response to customer emotions. Journal of Retailing, 76:285-308.

Forsyth, P. (2004). Locational and monopoly rents at airports: creating them and shifting them. Journal of Air Transport Management, 10:51-60.

Graham, A. (2009). How important are commercial revenues to today's airports? Journal of Air Transport Management, 15:103-148. 
Geuens, M., Vantomme, D. and Brengman M. (2004). Developing a typology of airport shoppers. Tourism Management, 25:615-622.

Lu, C.-C. and Pagliari, R. I. (2004). Evaluating the potential impact of alternative airport pricing approaches on social welfare. Transportation Research Part E, 40:1-17.

Mayer, C. and Sinai, T. (2003). Network effects, congestion externalities, and air traffic delays: Or why all delays are not evil. American Economic Review, 93:1194-1215.

Morrison, S. A. and Winston, C. (2007). Another look at airport congestion pricing. American Economic Review, 97:1970-1977.

Niskanen, E. (1986). Congestion tolls and consumer welfare. Transportation Research Part B, 21B:171-174.

Oum, T. H., Zhang, A., and Zhang, Y. (2004). Alternative forms of economic regulation at airports. Journal of Transport Economics and Policy, 38:217-246.

Pels, E., Nijkamp, E. and Rietveld, P. (2003). Access to and competition between airports: A case study for the San Francisco Bay area. Transportation Research Part A, 37:71-83.

Pels, E. and Verhoef, E. T. (2004). The economics of airport congestion pricing. Journal of Urban Economics, 55:257-277.

Rowley, J. and Slack, F. (1999). The retail experience in airport departure lounges: Reaching for timelessness and placelessness. International Marketing Review, 16:363-375.

Starkie, D. (2001). Reforming UK airport regulation. Journal of Transport Economics and Policy, 35:119-135.

Starkie, D. (2008). Aviation Markets: Studies in Competition and Regulatory Reform. Ashgate.

Sulzmaier, S. (2001). Consumer-oriented business design: The case of airport management. PhysicaVerlag.

Tirole, J. (1988). The Theory of Industrial Organization. The MIT Press.

Thompson, B. (2007). Airport retailing in the UK. Journal of Retail and Leisure Property, 6:203211.

Timothy, D. J. and Butler, R. W. (1995). Cross-border shopping: A North American perspective. Annals of Tourism Research, 22:16-34.

Van Dender, K. (2007). Determinants of operating revenues at US airports. Journal of Urban Economics, 62:317-336.

Yang, H. and Zhang, A. (2011). Price-cap regulation of congested airports. Journal of Regulatory Economics, 39(3):293-312.

Zhang, A. and Zhang, Y. (2003). Airport charges and capacity expansion: Effects of concessions and privatization. Journal of Urban Economics, 53:54-75.

Zhang, A. and Zhang, Y. (2006). Airport capacity and congestion when carriers have market power. Journal of Urban Economics, 60:229-247.

Zhang, A. and Zhang, Y. (2010). Airport capacity and congestion pricing with both aeronautical and commercial operations. Transportation Research Part B, 44:404-413. 